\title{
The Indochinese members of the Onthophagus (Parascatonomus) aurifex species group (Coleoptera: Scarabaeidae), with the description of a new species
}

\author{
SERGEY TARASOV ${ }^{1,2}$, JAN KRIKKEN $^{3}, \&$ JOHANNES HUIJBREGTS $^{3}$ \\ ${ }^{\prime}$ Department of Entomology, Natural History Museum of Denmark/University of Copenhagen, Zoological Museum, \\ Universitetsparken 15,DK-2100 Copenhagen,Denmark.E-mail:sergxf@yandex.ru \\ ${ }^{2}$ Institute of Natural Science, Kaluga State Pedagogical University, Stepana Razina str. 26, Kaluga 248023, Russia. \\ ${ }^{3}$ National Museum of Natural History Naturalis, P.O. Box 9517, 2300 RA Leiden, The Netherlands
}

\begin{abstract}
The representatives of Onthophagus (Parascatonomus) aurifex species group from Indochina are reviewed and a new species of this group, $O$. (Parascatonomus) alexeevi sp. n., is described. Distribution data for all treated species are provided.
\end{abstract}

Key words: Onthophagus, Parascatonomus, Indochina, new species

\section{Introduction}

The representatives of the dung beetle genus Onthophagus Latreille, 1802 belonging to the O. aurifex species group (in the subgenus Parascatonomus Paulian, 1932) inhabiting Sundaland (the biogeoraphic region of Southeastern Asia that comprises the Malay Peninsula and maritime southeast Asian islands of Sumatra, Java, Borneo, with surrounding smaller islands) were recently defined and reviewed by Krikken and Huijbregts (2008). In the Sundaland region this group includes six species, most of which can be reliably distinguished using aedeagal characters. Such subtle limits between species in this group often cause misidentifications. These circumstances induced us to take a closer look at material of the $O$. aurifex species group from the adjacent Indochina region, to which up until now were identified uncritically using the names of Sundaland species. This paper deals with what is defined as the $O$. aurifex species complex of the same named species group. The examination of Indochinese material led to the recognition of one new species and new records for the $O$. aurifex species complex.

\section{Materials and methods}

Specimens and collections

The material examined in the present study is kept in the following institutions:

BMNH The Natural History Museum, London, United Kingdom (M. Kerley \& M. Brendell)

RMNH National Museum of Natural History, Leiden, The Netherlands (J. Krikken \& J. Huijbregts)

ZISP Zoological Institute, St.-Petersburg, Russia (A. Frolov)

ZMUC Zoological Museum (Natural History Museum of Denmark), University of Copenhagen, Denmark (A. Solodovnikov \& O. Martin)

ZMUM Zoological Museum of Moscow State University, Russia (A. Gusakov) 


\section{Microscopy and illustrations}

All photos were taken with a digital camera attached to a dissecting microscope (Leica MZ16A ${ }^{\circledR}$ ). Male aedeagi in Figs. 2a-e, g-h, k-m were photographed in glycerin. First, the dissected aedeagus was macerated in $10 \%$ solution of $\mathrm{KOH}$ for several hours and then rinsed with distilled water. Finally, the aedeagus was placed in glycerin for storage. Male aedeagi in Figs. $2 \mathrm{f}$, $\mathrm{j}$ were photographed after they were dried and glued on a mounting triangle for storage.

\section{Discussion of the $O$. aurifex group distribution}

The $O$. aurifex species group was recently defined by Krikken and Huijbregts (2008). Here, we tentatively divide this group into two complexes of species based on the coloration of upper side of body: the $O$. aurifex complex and the $O$. sarawacus complex. The species within these complexes can usually only be reliably identified by aedeagal characters. The $O$. aurifex complex has species with upper side of forebody shiny metallic, i.e. their head and pronotum are cupreous and/or shiny green. This species complex includes 4 species: O. alexeevi sp. n.; O. aurifex Harold, 1877; O. semiaureus Lansberge, 1883; and $O$. semifex Krikken $\&$ Huijbregts, 2008. The $O$. sarawacus complex includes species with an entirely black upper side of the body: O. liewi Ochi \& Kon, 2005; O. muticifrons Endrödi, 1973, O. sarawacus Harold, 1877; and $O$. sumawacus Krikken \& Huijbregts, 2008. In this paper we limit our coverage only to the species of $O$. aurifex complex distributed in Indochina. The only species of $O$. sarawacus complex in Indochina is $O$. muticifrons Endrödi, 1973, which is apparently widespread. Its taxonomic status and infraspecific variation, however, would require separate research and are not considered in this paper.

The examination of the Indochinese material revealed that the $O$. aurifex complex beyond Sundaland consists of two different taxa, $O$. semifex and $O$. alexeevi. The record of $O$. aurifex from West Thailand (Kabakov \& Napolov 1999) is erroneous. We have reexamined the material (deposited at ZISP) on which that record is based and concluded that it belongs to the new species, O. alexeevi, described below. Although we have not studied the material concerned, we suggest that the record of $O$. semiaureus from Central Thailand (Masumoto 2002) is also based on misidentification. We believe that $O$. semiaureus only occurs in Sundaland because we have not found anything like it among the many specimens we examined from Indochina. The records of $O$. semiaureus from Indochina were likely based on misidentified specimens of either $O$. alexeevi or $O$. semifex. The latter was described from mainland North Sumatra and here we provide records (Fig. 3) from the Sumatran West Coast Islands (Sipura), the Malay Peninsula (Singapore and Kuala Lumpur), and South Vietnam (Cat Tien National Park). It is noteworthy that the specimens of the Vietnamese population of O. semifex are slightly different in the shape of their aedeagus (Figs. 2d-e) from those known from Sundaland. Thus, herein we tentatively assign the representative of Vietnamese population to the species $O$. semifex. In our view, these differences are too slight to justify the designation of a separate taxon for that population. Based on our observations, all previous records of species hitherto placed in the $O$. aurifex complex from Indochina are erroneous due to misidentifications. Only two species mentioned above, one recently described and one herein described, are found so far in Indochina, indicating how limited is our knowledge of the beetle fauna of this biodiversity hotspot.

The distribution map of all species in the $O$. aurifex complex based on the material available to us is provided in Fig. 3. Species in the $O$. aurifex group can usually only be distinguished by the aedeagal characters, and sometimes populations within one species slightly differ in the shape of aedeagus from each other (Krikken \& Huijbregts 2008). This combined with the small distribution range typical of species in this group, might indicate that a relatively short periods of isolation lead to rapid speciation. 
Onthophagus (Parascatonomus) alexeevi Tarasov, Krikken \& Huijbregts sp. n.

(Figs. 1, 2g-k, l)

Material examined. Holotype (ZMUC), male major bearing the following labels:

1. White, printed: S[outh] CAMBODIA Sianoukville $\mathrm{h}=50-150 \mathrm{~m} 3$ carrion traps disturb tropical forest 12-16.05.2008 leg. S. Tarasov

2. Orange, printed: HOLOTYPUS Onthophagus (Parascatonomus) alexeevi S. Tarasov, J. Krikken \& J. Huijbregts det. 2009

Paratypes: 53 specimens, South Cambodia, Sianoukville h=50-150m, 3 carrion traps disturb tropical forest, 12-16.05.2008 leg. S. Tarasov (ZMUC); $1 \sigma^{\star} \& 1$ 우, Thailand, Umphang river, 16.07N 99.00E, h1000m, 28/4-6/5.91 leg. D. Kral (ZISP); $2 \sigma^{*}$, W Thailand, 300m, Thung Yai Wildlife Sanctuary, 15.28N 98.48E, Tak Province, Umphang District, Song Bae Stream, 18-27.4.1988, M.J.D. Brendell, FIT B (RMNH); 1 ㅇ, same data and locality, but carrion trap (fish) (BMNH); $10^{x} \& 1$ i same locality and date, but evergreen rain forest M.J.D. Brendell, (BMNH); $20^{\star} \& 1$ 우, W Thailand, 300m, Thung Yai Wildlife Sanctuary, 15.30N 98.48E, Tak Province, Umphang District, Mae Chan/Mae Klong confluence, 27.4-6.5.1988, M.J.D. Brendell, oak/bamboo forest (BMNH); $10^{x}$ same data and locality, but edge of Karen clearing (BMNH).

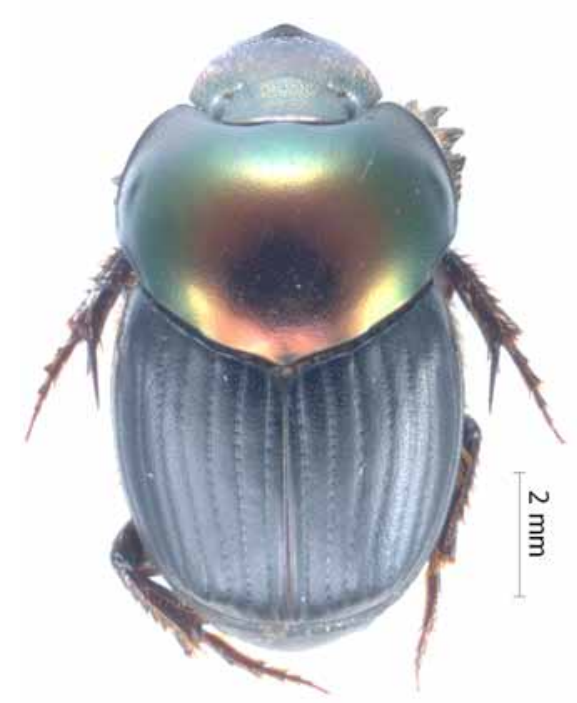

FIGURES 1. Onthophagus (Parascatonomus) alexeevi, dorsal view, holotype.

Description. Head and pronotum cupreous or with greenish metallic luster, elytra black, matt, underside black with metallic cupreous or/and green luster. Length 9.0-11.5 mm.

MALE major (Fig. 1). Head rounded; clypeal margin anteriorly distinctly reflexed, apex with short tooth, tip rounded; frontoclypeal ridge slightly expressed as smooth arcuate strip; clypeus densely, transversely rugulate; vertex simple with slightly protruding plate; eyes completely divided by canthus.

Pronotum convex, with slightly steeper anterior declivity in major specimens; anterior and lateral sides of pronotum marginate, base marginate only laterally and medially angulate; anterolateral pronotal angle slightly obtuse; pronotal disc covered with small, simple, sparse punctures (separated by 1-2 puncture diameters) becoming denser and granulose laterally; anterior part of propleura with ridge reaching prosternal lateral side.

Elytra with short, yellow, fine setae; sparsely covered with small, simple punctures.

Metasternum anteriorly raised, prow-shaped.

Protibia with 4 outer teeth, apico-internal angle with small tooth; apical spur modified in males: small, acuminate, slightly bent downward and inward; mesotibial and metatibial apex bearing short setae.

Aedeagus as in Figs. 2g-k, 1 (Fig. 2g is of the holotype).

FEMALE. Head and pronotum armature do not differ from those of males.

VARIATION. Slightly expressed in minor specimens by flatter pronotum with slightly denser punctation. 
HOLOTYPE. The body coloration and length of the holotype as follows; head and pronotum cupreous with greenish metallic luster, underside black with metallic cupreous and green luster. Length $9.7 \mathrm{~mm}$.
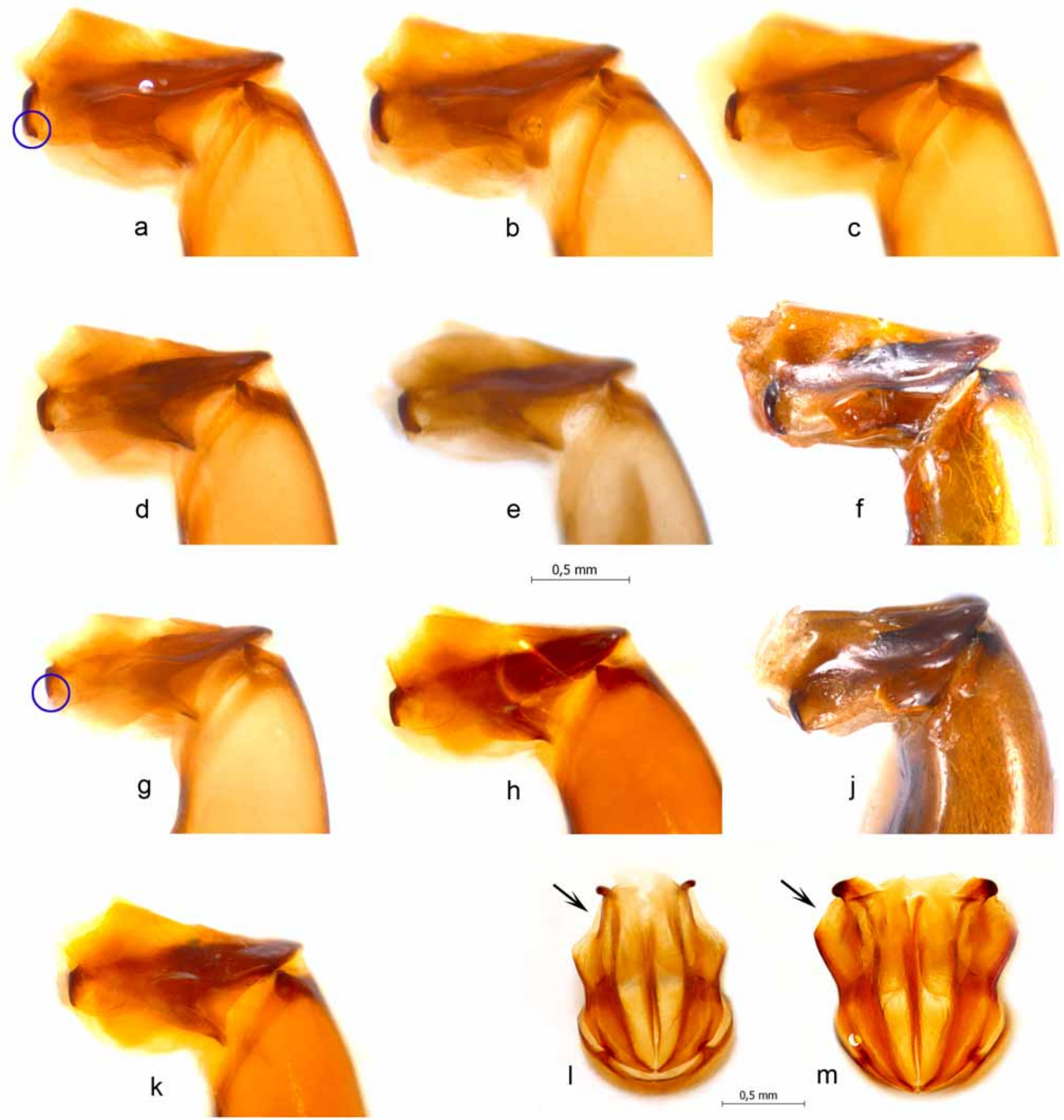

FIGURE 2. Aedeagi of $O$. aurifex-group species. a-f, $\mathrm{m}-O$. semifex (a-c, $\mathrm{f}, \mathrm{m}-$ paratypes, $\mathrm{d}-\mathrm{e}-\mathrm{Vietnam}$ ); $\mathrm{g}-\mathrm{l}-$ O. alexeevi ( $\mathrm{g}-\mathrm{j}, \mathrm{l}$ - paratypes, $\mathrm{k}$ - holotype); $\mathrm{a}-\mathrm{k}$ - aedeagus lateral view; $1-\mathrm{m}$ - aedeagus dorsal view; $\mathrm{a}-\mathrm{e}, \mathrm{g}-\mathrm{h}, \mathrm{k}-$ $\mathrm{m}$ - aedeagus photographed in glycerin; $\mathrm{f}, \mathrm{g}$ - aedeagus photographed after drying.

Differential diagnosis. The new species is most similar to three other species of $O$. aurifex complex: $O$. semifex, $O$. semiaureus and $O$. aurifex, which also have the upper side of the forebody shiny metallic. This is in contrast to the other species of the $O$. aurifex group belonging to $O$. sarawacus complex, which have an entirely black dorsal surface. The new species can only be reliably separated from these three species using the aedeagus. Among these three species, the aedeagal shape of $O$. alexeevi is most similar to that of $O$. semifex but differs in the sclerotized anterior part of parameral apex, which is thinner and without the lower 
tooth-like short appendage (Figs. 2 g-k, in Figs. 2g, j indicated with circle) present in O. semifex (Figs. 2a-f, in Figs. 2a, $\mathrm{f}$ indicated with circle). Onthophagus alexeevi also has the membranous surface of paramere preapically excavated (Fig. 21 indicated with arrow, see also Fig. 2j) while this structure is not excavated in $O$. semifex (Fig. $2 \mathrm{~m}$ indicated with arrow, see also Fig. 2f). Although the morphological differences between two species are subtle, there is robust evidence of their specific separation. First, the differences in aedeagal shape are stable between two species in the large series of examined material. Second, these two species seems to be sympatric (Fig. 3) and thus the stable differences in aedeagal shape are not a product of geographical variation, which indicated the specific independence of two species. Third, both species are possibly ecologically isolated as they have not been so far collected at the same place (Fig. 3).

The new species differs from $O$. semiaureus and $O$. aurifex by the different shape and location of the sclerotized anterior part of the parameral apex (for details, see also Krikken \& Huijbregts 2008).

Etymology. The new species is named after Dr. Sergey Alexeev, Kaluga Regional Biological Center, Russia-thanks to whom, one of us (S.T.) became an entomologist. S.T. is much obliged to Dr. Sergey Alexeev for invaluable support and personal help at the beginning of his career, as well as for an interesting and enjoyable time in both expeditions and laboratory work at the Kaluga Regional Biological Center.

Distribution and ecology. The new species is known only from West Thailand and South Cambodia (Fig. 3), but is probably widespread in Indochina. All Cambodian specimens were collected in disturbed tropical forest by means of pitfall traps baited with dead fish.

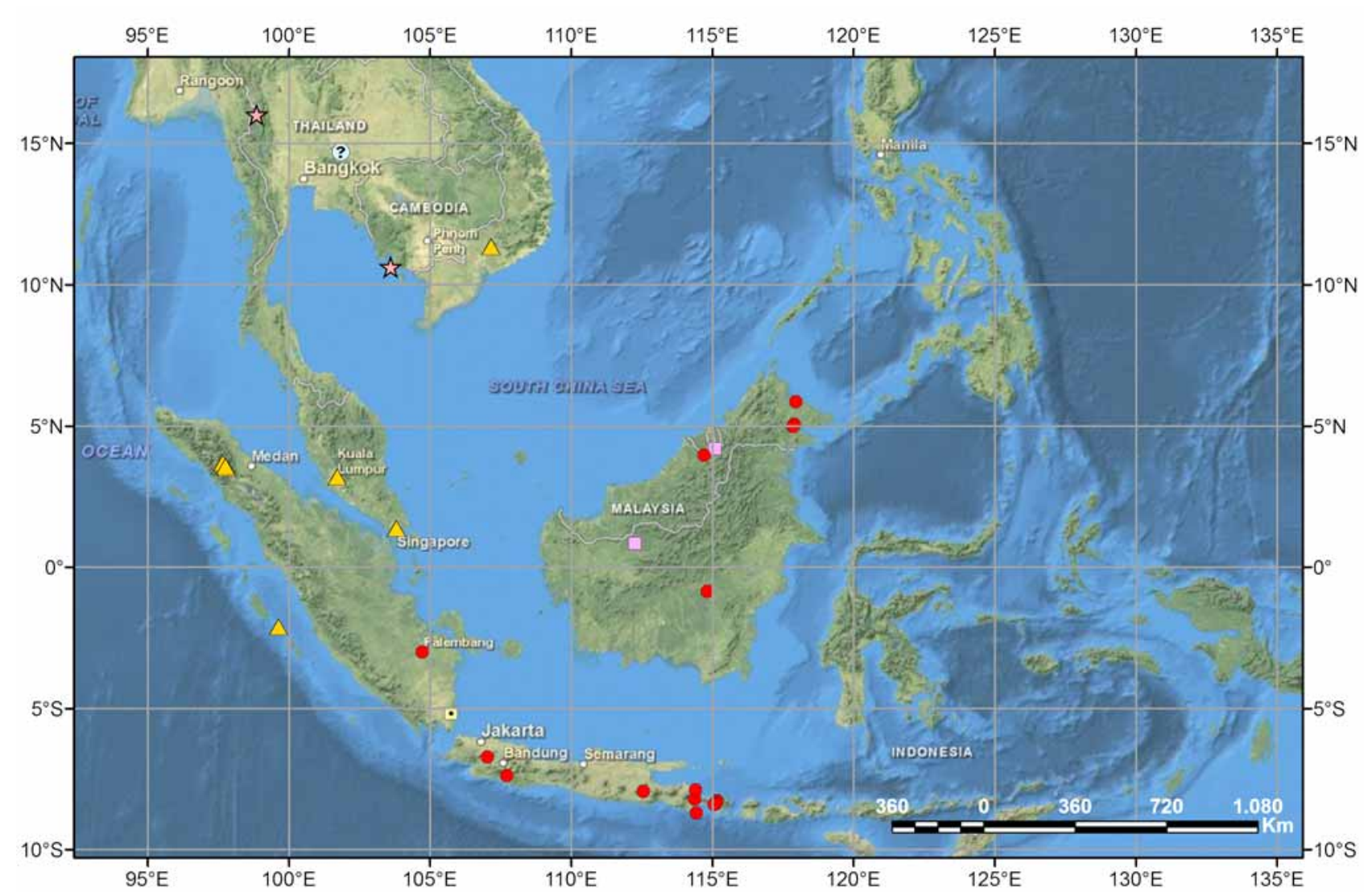

- O. semiaureus $\triangle$ O. semifex $\quad \square$ o. aurifex $\quad$ in Masumoto $(2002)$

$\square$ presumably new taxon, tentatively identified as $O$. aurifex (see Krikken \& Huijbregts 2008)

FIGURE 3. Distribution map of the species in the $O$. aurifex complex. 


\section{Acknowledgements}

We are grateful to Alexey Solodovnikov (ZMUC) for his support and the review of the manuscript. We thank Alexey Streltsov (Kaluga University, Russia) for making the field trip to Cambodia by Sergey Tarasov possible. We also thank Alexey Gusakov (ZMUM), Andrey Frolov (ZISP), Malcolm Kerley and Martin Brendell (BMNH) for making material under their care available for this study. We greatly appreciate the comments from one anonymous reviewer and Tristão Branco, which improved the manuscript. This paper is completed during the stay of one of us (Sergey Tarasov) as a visiting intern student at the Department of Entomology of the Natural History Museum of Denmark (ZMUC, Copenhagen) under financial support from the grants US NSF DEB-0715705 awarded to A. Solodovnikov (ZMUC) and A. Newton (FMNH) and from the frame grant 27989 of the Department of Entomology at ZMUC awarded to Thomas Pape. Overall support of that Entomology Department at Copenhagen is appreciated. This research received support from the SYNTHESYS Project: http://www.synthesys.info/, which is financed by European Community Infrastructure Action under the FP7 Integrating Activities Programme.

\section{References cited}

Kabakov, O.N. \& Napolov, A. (1999) Fauna and ecology of Lamellicornia of subfamily Scarabaeinae (Coleoptera, Scarabaeidae) of Vietnam and some parts of adjacent countries: South China, Laos and Thailand. Latvijas Entomologs, 37, 58-96.

Krikken, J. \& Huijbregts, J. (2008) Distinguishing the Sundaland species in the Onthophagus (Parascatonomus) aurifex group (Coleoptera: Scarabaeidae: Scarabaeinae). Tijdschrift voor Entomologie, 151, 173-185.

Masumoto, K. (2002) New record of Onthophagus semiaureus Lansberge from Thailand. Elytra, $30,172$. 